\title{
Research of high-performance harvesting and transport equipment
}

\author{
Galia Kokieva ${ }^{1, *}$, Yrii Dondokov ${ }^{2}$, Daria Stepanova $^{1}$, Alexei Stroyev $^{2}$, and Alexander \\ Filatov $^{1}$ \\ ${ }^{1}$ The Arctic State Agrotechnological University, 3, sh. Sergelyakhskoe 3 km, 677007, Yakutsk, the \\ Republic of Sakha (Yakutia), Russia \\ ${ }^{2}$ The North-Eastern Federal University named after M.K. Ammosov, 58, st.Belinskogo, 677007, \\ Yakutsk, the Republic of Sakha (Yakutia), Russia
}

\begin{abstract}
The question of applying the most progressive technologies of cleaning work of efficient systems of machines is of paramount importance. In solving tasks to ensure the sustainable development of agricultural production, reliable supply of the population of the country, food in food is an important place to strengthen the material and technical base of the agro-industrial complex, its targeted technical re-equipment. In this regard, the goal of the work is to study the rational method of increasing the performance of the screw screw conveyor, allowing you to create a small-sized structure, is an increase in its revolutions. The article provides research in the method of increasing the performance of the screw screw conveyor, allowing you to create a small-sized design by increasing its revolutions. The technology of the work of conveyors-grab trucks was described, the work mechanism was investigated and the disadvantages of work were described, namely, in defective providing the possibility of grain transfer over long distances along the spatial track or complicates the technological scheme. Such an organization of harvesting on the scale of the country involves the creation and implementation of several systems of high-performance cleaning and transport equipment primarily in the main grain areas.
\end{abstract}

\section{Introduction}

A number of research and design organizations deal with the automation of post-harvest grain processing processes. However, they often make inconsistent decisions. The development of technology and machines for harvesting grain crops takes place without taking into account the biological characteristics and dynamics of the accumulation of dry grain mass, which stops at a humidity of $35 \ldots 40 \%$. The grain harvested during this period

\footnotetext{
${ }^{*}$ Corresponding author: kokievagalia@mail.ru
} 
has the best sowing and food qualities. Grain harvesting by modern combine harvesters begins no earlier than 7-10 days after reaching the maximum yield by dry weight of grain. To ensure the sustainability of the process of harvesting and processing the grain crop in various regions of the country, a complex of technological, technical and organizational measures is necessary, the implementation of which should determine the economically justified degree of risk, taking into account the natural, climatic and production conditions. The most rational way to increase the productivity of a screw screw conveyor, which allows you to create a small-sized structure, is to increase its speed $[1,8,15]$. The productivity of the screw also depends on the uniformity of the grain supply. When using hopper feeders and similar feeders, the bulk material enters the conveyor through the intake chamber window from above and part of it is discarded by the ascending branch of the screw. Therefore, the material enters the auger in portions that depend quantitatively on the revolutions, the angle of inclination of the auger to the horizon and the coefficient of internal friction of the material. However, all these designs do not provide the possibility of transferring grain over long distances along a spatial route or complicate the technological scheme[2,9,15].Most spiral conveyors do not provide for changing the distance and trajectory of the material movement. In addition, when working with them during loading directly from the shoulder, manual labor or additional equipment is required. When the grain is captured from the mound, with an increase in the speed of rotation of the spiral, it is scattered, and resistance to axial movement is created inside the casing [3,7,9]. As a result of excessive mixing of the material and turning of the grain inside the spring screw. In this regard, the limit of the increase in productivity under the existing principle of transportation was reached.

\subsection{Purpose of the work}

In solving the tasks of ensuring the sustainable development of agricultural production, reliable supply of food to the population of the country, an important place is given to strengthening the material and technical base of the agro-industrial complex, its purposeful technical re-equipment. In this regard, the purpose of the work is to study a rational way to increase the productivity of a screw screw conveyor, which allows you to create a smallsized structure, is to increase its speed.

\section{Results and discussion}

The practice of mass application of grain-sowing areas of the self-propelled combine as the main machine is increasingly revealing the weak side of its concept. Farms, especially specialized grain farms, persistently and fairly demand that the harvester must simultaneously collect and export straw, even grind it, while harvesting the grain part of the crop. After all, these works now spend three to four times more labor than for harvesting grain. At the same time, most of the straw is lost, while animal husbandry is experiencing serious difficulties due to the lack of cheap coarse feed and bedding. The piles of straw that remain on the field after the passage of the self-propelled combine do not allow us to cultivate the soil in a timely manner, and for this reason, as has been said many times, we lose 3-4 tons of grain per hectare of the future crop. Numerous attempts to solve the problem of straw harvesting by self-propelled combines (mounted straw presses, various shredders and trailed carts for collecting straw) are met with serious difficulties. As practice has shown, combine harvesters with shredders and trolleys are overloaded, their productivity decreases, and their maneuverability deteriorates. The increase in productivity with increasing screw speed (from 400 to 1100 revolutions per minute) occurs up to a certain point, after which the speed continues to increase, and the productivity decreases 
(Fig. 1). Depending on the diameter of the screw $\mathrm{D}$, the maximum productivity shifts. When the angle of inclination to the horizon is $20^{\circ}$ and the grain humidity is $14-15 \%$, it is observed: in the screw having $\mathrm{D}=100 \mathrm{~mm}$ at $900-950 \mathrm{rpm}, \mathrm{D}=125 \mathrm{~mm}-800-850 \mathrm{rpm}, \mathrm{D}=$ $150 \mathrm{~mm}-700-725 \mathrm{rpm}$.

Using experimental data, we will make a parametric equation of the grain trajectory:

$$
\left.\begin{array}{rl}
x & =R \cos \theta, \\
y & =R \sin \theta, \\
z & =\frac{s_{3}}{2 \pi}\left(\theta+\frac{\pi}{6} \sin \theta\right),
\end{array}\right\}
$$

where R- is the average radius of the annular projection of the grain screw on the XOY plane; $S_{z}$ is the pitch of the grain screw; $\theta=\omega_{z} t$-is the angle of rotation; $\omega_{z}$-is the angular velocity of the grain; $t$ is the time of rotation. The expression pi/ $6 \sin \theta$ is determined from the following conditions: for $z=0 y=0$, for $z=S z / 3 y=R$.

If these requirements are met, the projections of the grain trajectory on the ZOY and ZOX planes will be asymmetric and periodic in $\mathrm{z}$ (with a period equal to Sz). The projection of the trajectory on the XOY plane will have the form of a circle with radius $\mathrm{R}$. From the projection of the trajectory on the ZOY plane, as in the experiments, it follows that the angular velocities of the ascending and falling branches of the grain screw are different: when lifting, the velocity $\mathrm{w}_{\mathrm{z}}$ is less than when dropping. In addition, it is unstable and varies from minimum to maximum[4]. When operating a high-speed screw, the axial speed of the grain $v_{z}$ lags behind the axial speed of the screw $v_{z}$. This lag can be expressed by the coefficient $k_{v}$, which must be taken into account when calculating the performance of a high-speed conveyor [3-5]:

$$
k_{v}=\frac{v_{3}}{v_{z}}, \quad v_{3}=k_{v} \frac{s n}{60},
$$

where $\mathrm{S}$ and $\mathrm{n}$ are the pitch and the number of revolutions of the screw. The coefficient $\mathrm{k} \_v$ can also be determined in terms of the angular velocities of the grain $\omega_{z e r}$ and the screw $\bar{\omega}$ :

$$
k_{v}=\frac{\omega_{3 \mathrm{ep}}}{\omega}
$$

The value $k_{v}$ obtained experimentally for a horizontal screw and grain with a moisture content of $14-15 \%(f=0.35-0.40)$ is $0.57-0.60$.

At high screw speeds, the transported material forms a helical surface, the ascending $\mathrm{AB}$ and the falling $\mathrm{BC}$, the branches of which (Fig.1) have different angles of inclination to the screw axis $Z\left(\delta=57-60^{\circ}, \gamma=38-40^{\circ}\right)$. For one revolution of the high-speed screw, the ascending branch of it moves the material along the axis by two - thirds of the pitch of the grain screw $\mathrm{Sa}$, and the discharged one-third. The first branch tends to throw the material up and forward, the second-steeply down under the screw. 


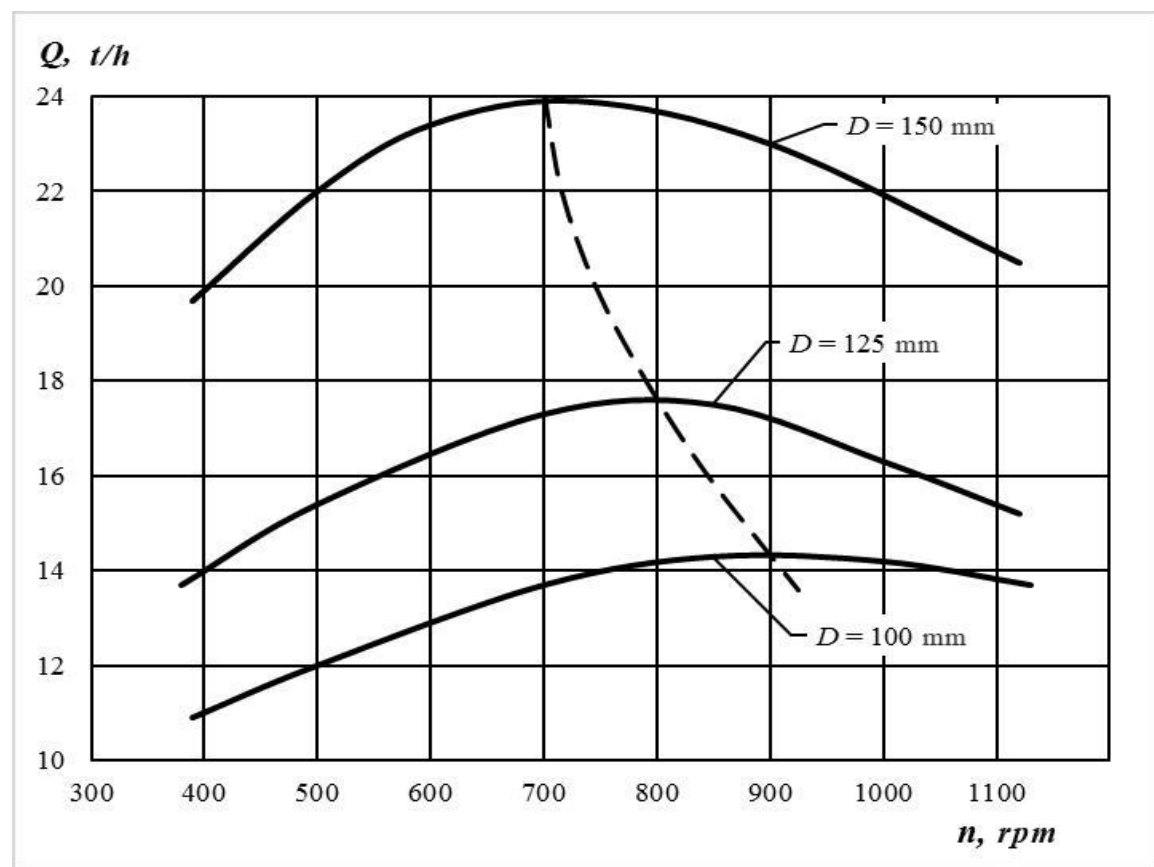

Fig. 1. Change in the productivity of the high-speed screw depending on the turnover and screw diameter.

This is explained by the fact that at high speeds, the bulk material (grain), thrown by the centrifugal force to the inner surface of the pipe, fills the grooves [6]. Since they are located quite close to each other (after $30^{\circ}$ ), a braking layer is formed at the surface, under the influence of which the circumferential component of the speed of the absolute movement of the grain decreases, and the axial component increases[6,7,10].Let's analyze the flow of grain into the screw depending on the speed of the screw. With some assumption, we assume that the condition under which the largest amount of material will pass into the intake chamber is expressed in $[11,13]$ :

$$
v_{\text {okr }} \leq v_{\text {ist }}
$$

where $v_{o k r}-$ is the circumferential speed of the screw edge of the auger; and $v_{\text {ist }}$ is the speed of grain outflow from the hopper. Under this condition, the grain will be discarded less by the upper branch of the screw, and it will enter the screw mainly due to the discarding branch [12-14]. It is known that the formula (4) does not reflect the nature of the change in the productivity of the screw conveyor when working at high (more than 300-400 per minute) revolutions and therefore needs adjustments $[2,6,10]$. Based on our research, the performance of a high-speed screw can be determined as follows:

$$
Q=47,1 D^{2} \operatorname{Snk}_{v} \psi \gamma c t / h \text {. }
$$

Using experienced data, express the filling coefficient $\psi$ :

$$
\psi=1-A \frac{n}{1000}
$$

where a is the proportionality coefficient.

For auger $\mathrm{D}=100 \mathrm{mma}=0.40, \mathrm{D}=125 \mathrm{~mm} \mathrm{a}=0.50$ and $\mathrm{D}=150 \mathrm{~mm} \mathrm{~A}=0.58$.

We substitute in formula (5) the average value $\mathrm{k}_{v}=0.6$ and the value of $\psi$, expressed throughn 


$$
Q=28,2 D^{2} \operatorname{Sn}\left(1-A \frac{n}{1000}\right) \gamma c .
$$

We will determine the screw speed corresponding to the optimal conditions for the material entering the conveyor. Let's write an expression for the speeds:

$$
\begin{aligned}
& v_{i s t}=\sqrt{\frac{g R_{g}}{f}}, \mathrm{~m} / \mathrm{s}, \\
& v_{o k r}=\frac{\pi R_{v} n}{30}, \mathrm{~m} / \mathrm{s},
\end{aligned}
$$

where $\mathrm{R}_{\mathrm{g}}$ is a hydraulic radius of the opening of the expiration, $\mathrm{m}$; $\mathrm{F}$ - is the internal friction coefficient of the material; G-acceleration of the free fall, $\mathrm{m} / \mathrm{s}^{2} ; \mathrm{R}_{\mathrm{V}}$ - the radius of the screw screw, $\mathrm{m}$.

We equate the right parts of these equations and solve the resulting expression relative to the number of screw revolutions:

$$
n=n_{o p t}=\frac{30}{\pi R_{v}} \sqrt{\frac{g R_{g}}{f}} .
$$

Express condition (1) through the speed ratio:

$$
\frac{v_{i s t}}{v_{o k r}}=\varepsilon=\frac{30}{\pi R_{v} n} \sqrt{\frac{g R_{g}}{f}}
$$

and let's call $\varepsilon$ - the coefficient of penetration possibility. The values of it, counted at different revolutions of the screw $\mathrm{n}$ and $\mathrm{R}=0.17 \mathrm{~m}, \mathrm{~F}=0.5$ (grain), $\mathrm{R} \_\mathrm{B}=0.62 \mathrm{~m}, \mathrm{v}_{\text {ist }}=$ $1.8 \mathrm{~m} / \mathrm{s}$ are shown in Table 1.

Table 1.Factors affecting the performance of the auger

\begin{tabular}{|l|c|c|c|c|c|c|c|c|}
\hline \multirow{2}{*}{ Indicators } & \multicolumn{7}{|c|}{ Number of screw speed per minute } \\
\cline { 2 - 9 } & 300 & 500 & 700 & 900 & 1100 & 1300 & 1500 & 3000 \\
\hline $\begin{array}{l}\text { District speed } \\
\text { screwv }\end{array}$ okr, $\mathrm{m} / \mathrm{s}$ & 1.8 & 3.14 & 4.4 & 5.6 & 7.0 & 8.2 & 9.5 & 19.0 \\
\hline $\begin{array}{l}\text { Penetrationcoefficient } \\
\varepsilon\end{array}$ & 0.94 & 0.57 & 0.41 & 0.32 & 0.26 & 0.22 & 0.19 & 0.09 \\
\hline Filling coefficient $\psi$ & 0.9 & 0.75 & 0.65 & 0.45 & 0.4 & 0.3 & 0.2 & - \\
\hline
\end{tabular}




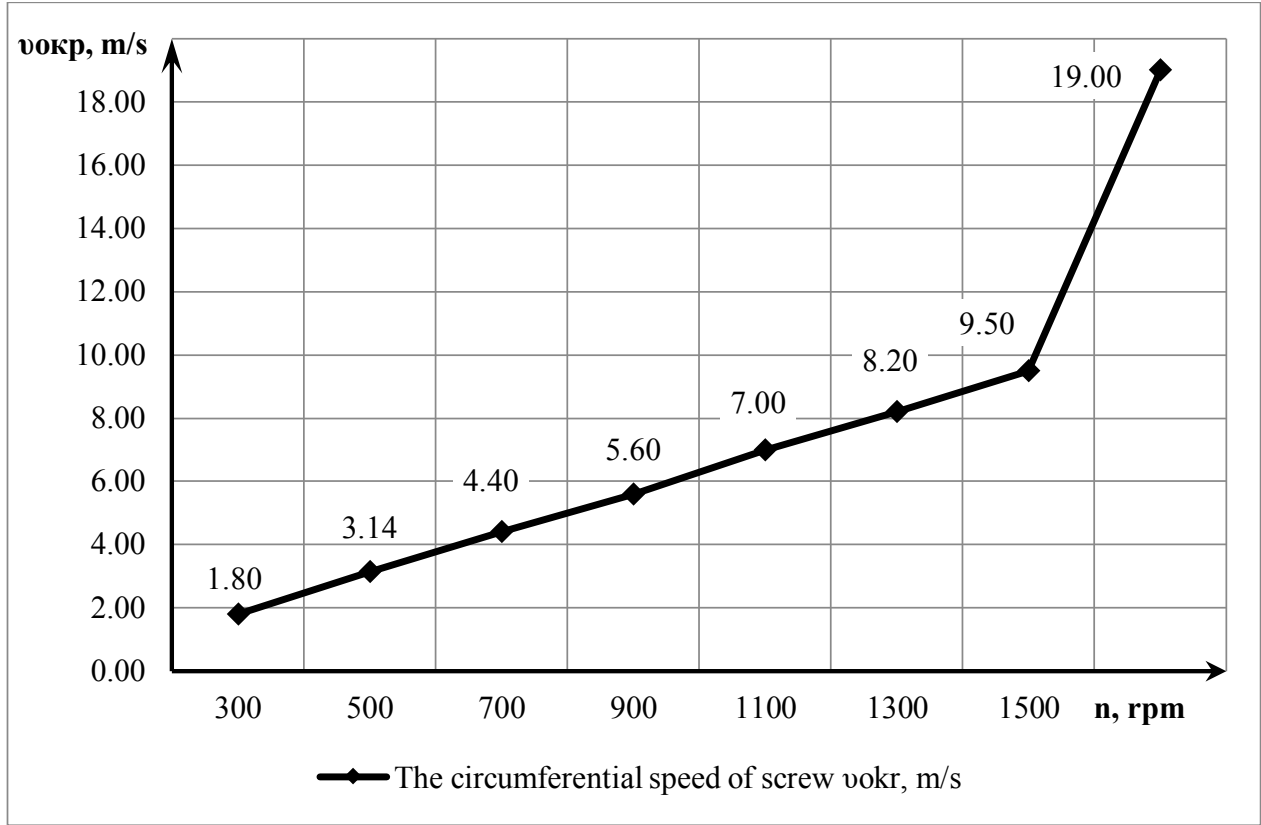

Fig. 2. Changing the circular screw speed.

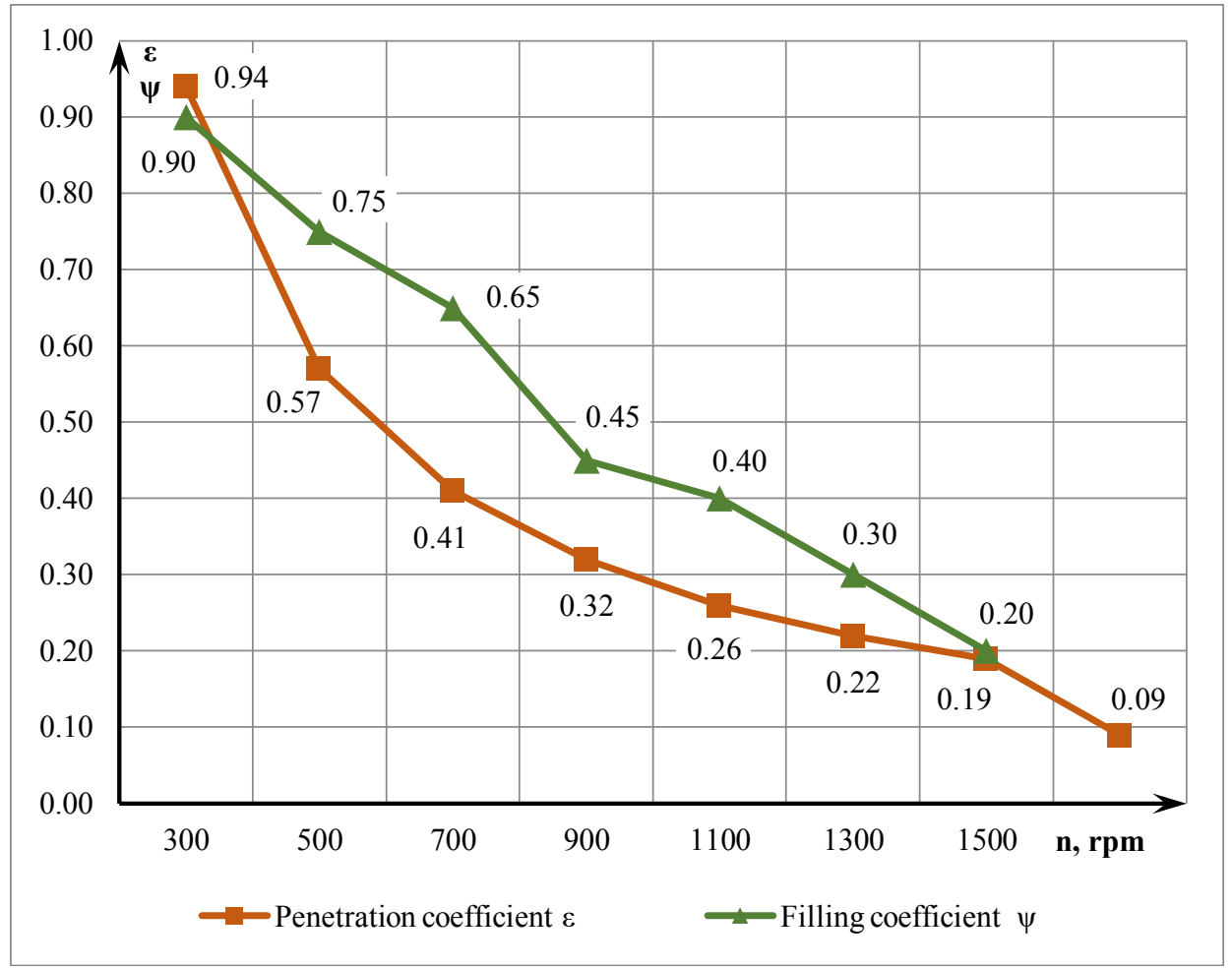

Fig. 3. Change in the penetration and filling ratio. 
From the graph, it can be seen that the value of $\varepsilon$ decreases with increasing revolutions. In this case, the filling coefficient of a screw grain is also reduced, which causes a decrease in performance. The performance coefficient $\rho$ and express as follows:

$$
\rho=k_{v} \psi \text {. }
$$

The value of $\rho$ can be increased by making a screw screw with a variable step [10]. In this case, a part of the screw, which comes to the intake chamber should have a step more less than the main (in our experiments he was half less). The existing design formula of the screw of the auger has the form:

$$
Q=60 \frac{\pi D^{2}}{4} \operatorname{Sn} \psi \gamma c, \mathrm{t} / \mathrm{h},
$$

where $\gamma$ is the volumetric weight of the material, $\mathrm{t} / \mathrm{m} 3 ; \mathrm{C}$ is a coefficient that takes into account the angle of the auger.

\section{Conclusion}

In solving the tasks of ensuring the sustainable development of agricultural production, reliable supply of food to the population of the country, an important place is given to strengthening the material and technical base of the agro-industrial complex, its purposeful technical re-equipment. A rational way to increase the productivity of a screw screw conveyor, which allows you to create a small-sized structure, is to increase its speed. To increase the productivity of the auger, it is necessary to accelerate the axial movement of the material, i.e. to stretch the ascending and, especially, falling branches of the material trajectory. Thus, further research will allow us to find new ways to increase the speed coefficient $\mathrm{k} \_v$ and the coefficient $\psi$ and to create high-speed, high-performance and smallsized screw grain conveyors.

\section{References}

1. T.A. Altukhova, Agrarian science, 3, 68-69 (2018)

2. T.A. Altukhova, S.V. Altukhov, S.N. Shukhanov, Proceedings of the International Academy of Agricultural Education, 50, 5-7 (2020)

3. M.V. Bugrov, A.T. Lebedev, Young Science, 2 (6), 14-17 (2015)

4. A.A. Dubovitsky, VIII International Scientific and Practical Conference Bryansk, March 17, 2017 - Bryansk State Agrarian University, 293-298 (2017)

5. N. Kirpa, Grain. Journal of the modern agroindustrial, 5 (2015)

6. A.T. Lebedev, D.I. Makarenko, Rural mechanic, 9, 14 (2011)

7. G.N. Polyakov, P.A. Boloev, S.N. Shukhanov, Agricultural science, 6 (5), 28-29 (2016)

8. G.N. Polyakov, S.N. Shukhanov, Topical issues of agricultural science, 35, 14-19 (2020)

9. M.A. Radzhabov, R.R. Mazanov, Collection of scientific papers of the All-Russian scientific and practical conference of students, graduate students and young scientists, Makhachkala, December 22 (2016) - Dagestan State Agrarian University named after I. M.M. Dzhambulatova, 187-189 (2017)

10. D.Z. Sadbekov, S.G. Akhmetov, A.S. Otto, E.V. Demchuk, Collection of the AllRussian (national) scientific-practical conference, Omsk, February 05 (2020 ) - Omsk State Agrarian University named after P.A. Stolypin, 272-277 (2020) 
11. G.L. Shavlyukevich, A.N. Skripko, T.V. Vernikovskaya, et al., Emergency situations: prevention and elimination, 2 (32), 104-109 (2012)

12. S.N. Shukhanov, Agrarian science, 1, 25-26 (2018)

13. S.N. Shukhanov, Bulletin of the agro-industrial complex of the Upper Volga region, 4 (36), 75-78 (2016)

14. A.R. Sukhaeva, Tidings of the International Academy of Agrarian Education, 46, 66-69 (2019)

15. S.N. Shukhanov, Tidings of the Orenburg State Agrarian University, 2 (58), 63-65 (2016) 